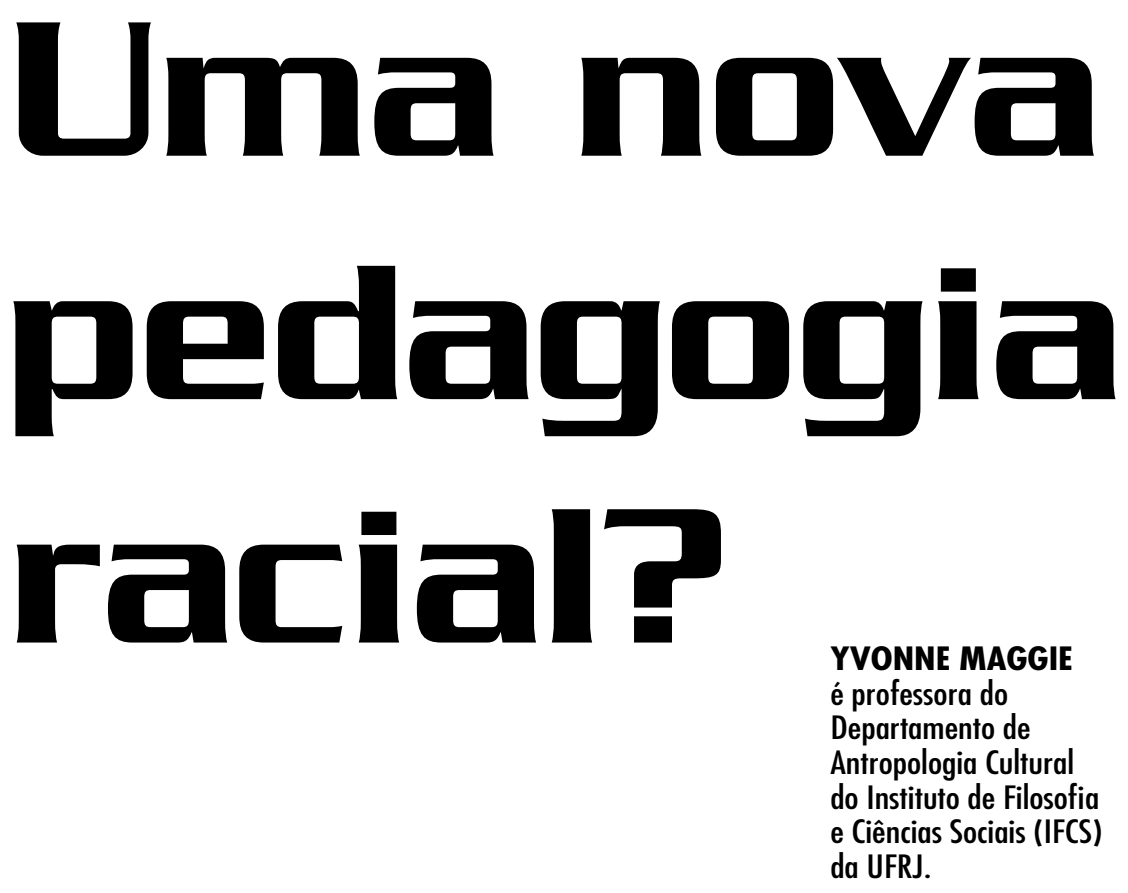

"BRASIL:

um país de grandes belezas.

de diversas raças e culturas.

misturadas harmoniosamente [...]"

[aluna da primeira ano da ensina médio, 2003].

\title{
“Mgleque negro
}

Aquele moleque que sobrevive

Coma manda a dia-a-dia

Tá na correria como vive a maioria negra desde a nascença

E escura se sau eu tô pra ver ali igual

Conhece uma pá de alucinada

Toda raça negra, como eu sou

A meta dele é acabar cam a panto final

A injustiça contra us negras, as pobres e a marginal

Se liga meu irmãa na que eu tenha a lhe dizer

Q racismo tá cam nada, vacê tem que pagar pra ver

Agora meu irmãa eu vau falar eu sou negra cam muita orgulho

Cala a oca [boca] chara [cara]"

[alına da primeira ana da ensina média, 2005]. 


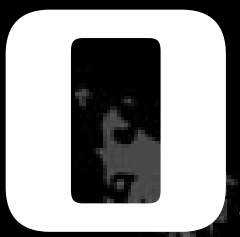

s dois poemas que abrem este artigo

foram escritos por alunos de uma escala estadual da Rio de Janeiro. 0 primeiro, de 2003, resultou de um concurso promovida por uma fábrica de automóveis. Já os versos do segundo, de 2005, foram feitos nas aulas de Atividade Complementar [Aticam]' nas quais estã̃a sendo introduzidas as Diretrizes Nacionais Curriculares para a Educação das Relaçães Étnico-Raciais e para a Ensino da História e Cultura Afro-Brasileira e Africana. A escola faz parte do universo da pesquisa sobre a impacto de políticas públicas em escolas de ensino médio do Rio de Janeiro que venho realizando desde agusto de 2004.

A pesquisa realizada em escolas do Rio de Janeiro se insere em um projeto maior - “Acompanhando as Açũes Afirmativas no Ensino Superior"ᄅ - e mobilizgu 20 estudantes de graduaçãa e pós-graduação que empreenderam 16 estudas de caso em escolas da rede estadual escolhidas entre as que foram classificadas com as piores indicadores a partir da avaliaçãa do Programa Nova Escola³.'Além desses casos selecionamos duas escolas da rede com bons índices para efeito comparativo. Incluímos também uma escola da rede federal que tem sido bem avaliada pelos indicadores de proficiência e repetência e uma escola da rede privada considerada uma boa escola. Estas duas últimas lacalizadas em bairros mais abastados da cidade. As escolas pesquisadas foram escolhidas de forma a representarem o universo das escolas urbanas do estado e também pela facilidade de acesso. Muitas dos pesquisadores estudaram nessas escolas localizadas em bairros pobres, em si-

Atividade Complementar é uma matéria para "preencher" - horário da grade escolar

A escola possui 26 turmas

112 de primeiro ano, 8 do

segundo ano e 6 do terceiro

ano) e todas elas possuem ao

menos um tempo de Aticom e

o que seria o ensino religioso

Dessa forma, todos os alunos

são contemplados com pelo

menos dois tempos semanais

de atividades relacionadas

ao projeto "Mitos e Tabus no

Culura Afro-Brasileira". Seja

através das aulas de História

da Cultura Afro-brasileira, seja

através das atividades de

educação arifísica ou trabalhos

e leituras feitos nas aulas com a

professora Lidia, que trabalho

no tempo do que seria o ensino

religioso. Aficom e ensino reli

gioso estãosempre seguidos um

do outro e aparecem na maio

parte das turmas nos dois úlitimos

tempos da grade horáriae antes

do recreio ou nos dois úlimos

tempos de aula.

A pesquisa em âmbito nacional é financiada pela Fundação Ford, CNPa e Faperi e coor denada por Antonio Sergio Guimarães (USP), Jocélio dos Santos (UFBA), Peter Fry (UFR)

e Yvonne Maggie. A Secretaria de Educação do Estado do Ria de Janeiro também financia e apóia parie desse projeto de acompanhamento de politicas públicas implantadas no estado desde agosto de 2004

O Nova Escola é um programa de avaliaçäofeitio pela Secreta ria de Educação do Estado do Rio de Janeiro nas escolas da rede e mede, por amostragem a proficiência dos estudantes em matemática e português, ofluxo dos alunos no sistema lrepetência e evasãol e a gestãoescolar. Esses indicadores servem para hierarquizar as escolas em quatio níveis. Os professores recebem gratificaçōes anuais conforme o nível em que sua escola foi classiticada. 


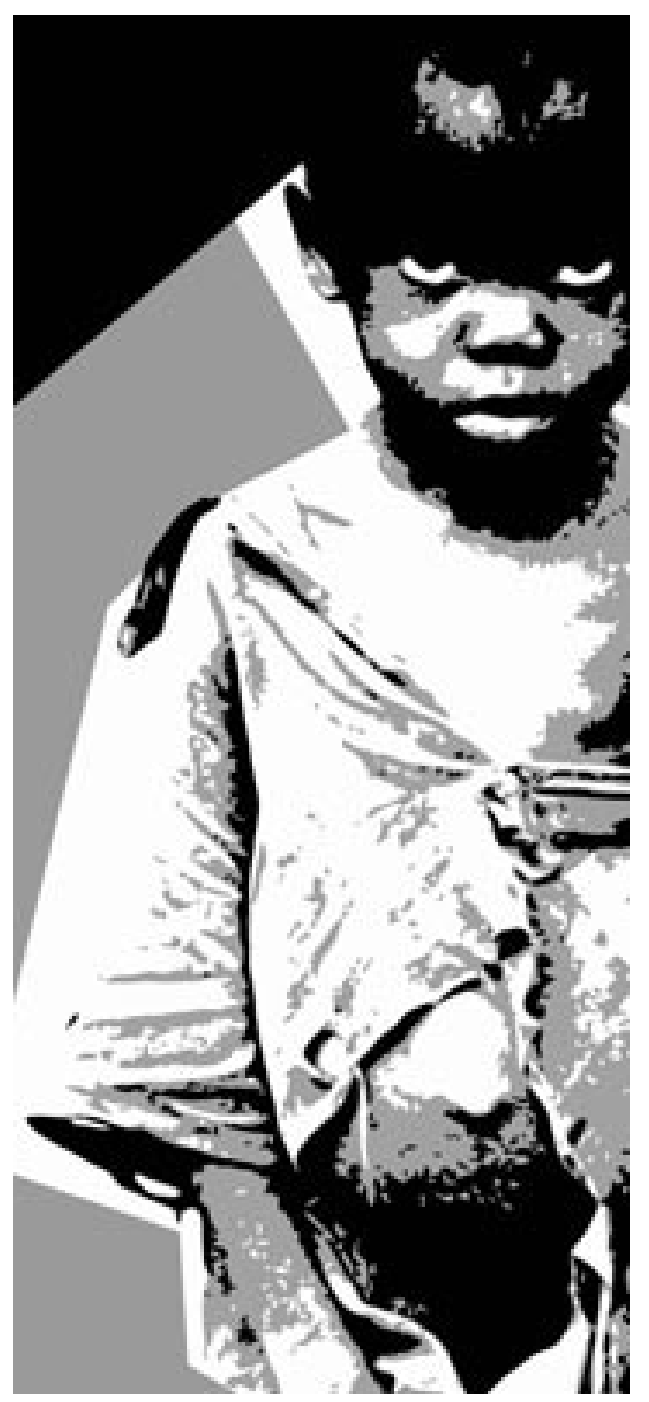

tuação de risco ou mesmo em bairros ricos, mas freqüentadas por jovens moradores de favelas próximas. A pesquisa buscou também, através de um levantamento quantitativo, mapear o universo pesquisado. $\mathrm{O}$ objetivo do levantamento era descrever a relação dos estudantes com a escola; o seu percurso na escola e os seus projetos futuros; suas percepções sobre o que é uma boa aula; sobre se tinham sofrido preconceito de algum tipo; sobre se tinham conhecimento das cotas ou reserva de vagas para estudantes negros, pobres, estudantes de escolas públicas e deficientes físicos no ensino superiore o que achavam dessa política; sobre o perfil dos estudantes por "raça", idade, sexo, série e trabalho; finalmente a posição socioeconômica dos respondentes. Os questionários foram aplicados em dezembro de 2004 a $179^{4}$ estudantes do primeiro ano do ensino médio das escolas pesquisadas como um pré-teste para o levantamento iniciado em novembro de 2005.

Nossa proposta neste artigo é descrever uma outra dimensão daquilo que foi chamado por Marcos Chor Maio e Ricardo Ventura Santos (2005) de "uma pedagogia racial" ao analisarem o vestibular da UnB de 2004, em que se adotou pela primeira vez o sistema de cotas raciais no qual se atribuiu a identidade das pessoas através de fotografia. "O vestibular da UnB transformou-se em uma espécie de 'pedagogia racial', de conversão indentitária de pardos e pretos em 'negros', culminando no trabalho da comissão encarregada de identificar os 'verdadeiros'beneficiários das cotas" (Maio \& Santos, 2005, p. 193) ${ }^{5}$.

Os autores descrevem as etapas desse processo. A primeira, conduzida por uma “espécie de equipe de anatomia racial", analisando as fotografias, decide quem é negro e quem não é. A segunda, composta por um tipo de comitê de "psicologia racial", escolhe, a partir de uma entrevista, aqueles que merecem ter essa identidade reafirmada ${ }^{6}$. O comitê, ou “tribunal racial", é composto por uma estudante e três representantes do Movimento Negro, além de um sociólogo e um antropólogo. Segundo Dione Moura, professora da UnB, o citado comitê teria que "olhar com os olhos da sociedade para beneficiar quem realmente deve participar do sistema [de cotas]" (Afonso, 2004 apud Santos \& Maio, 2005). Mas, além desses "olhos da sociedade" e desse "filtro social", a comissão, que julga quem tem o direito de ser negro no vestibular de cotas da UnB, legitima-se através da autoridade da ciência com a presença de um antropólogo.

$O$ vestibular da UnB, tão bem descrito pelos autores, e que funciona até hoje nos mesmos moldes, é um caso limite e tem um caráter de "exemplaridade" de "vitrine" e uma das peças de engenharia racial que se implantou no país a partir da participação do Brasil na III Conferência Mundial das Nações Unidas de Combate ao Racismo, Discriminação Racial, Xenofobia e Intolerância Correlata em 2001 em Durban (África do Sul). 
Nossa hipótese neste trabalho é de que as Diretrizes Curriculares Nacionais para a Educação das Relações Étnico-Raciais e para o Ensino de História e Cultura AfroBrasileira e Africana ${ }^{7}$ são uma outra dimensão desse processo de conversão identitária de pardos e pretos, morenos, escuros e a miríade de outras categorias em "negros".

Se o caso do "tribunal racial" da UnB produziu um debate e o pronunciamento de várias entidades científicas além de muitos antropólogos e cientistas ${ }^{8}$, as Diretrizes, aprovadas por uma comissão de especialistas composta por educadores de renome, produziram pouco debate a não ser por algumas vozes isoladas como as de José Roberto Pinto de Góes (2004) e Peter Fry (2005).

\section{UMA MICRO-HISTÓRIA DAS}

\section{MUDANC,AS PRODUZIDAS NAS CONCEPÇÕES SOBRE 0 TEMA E SUAS RELAÇOEES COM 0 APARATO BUROCRÁTICO DO ESTADO}

Tanto as Diretrizes quanto as chamadas ações afirmativas têm uma história na sua intrincada relação como aparato burocrático do Estado. Passamos agora a descrever um dos níveis dessa micro-história.

Em 1999 o Ministério da Educação publicou o livro Superando o Racismo na Escola, uma coletânea organizada pelo antropólogo Kabengele Munanga (2005) que reúne trabalhos de 14 professores, estudiosos das relações raciais e ativistas do Movimento Negro sobre o racismo nas escolas, seus efeitos e modos de combatê-lo. O livro visa a auxiliar mestres e gestores na difícil tarefa de enfrentar o racismo nas escolas.

A primeira edição veio prefaciada pelo então ministro Paulo Renato Souza, em cuja gestão foram elaborados os parâmetros curriculares nacionais que propunham temas transversais às disciplinas. $\mathrm{O}$ prefácio de Paulo Renato, escrito em 1999, define em um primeiro parágrafo a tônica ou a ênfase que estava sendo dada, na época, à questão do combate ao racismo:

"A formação cultural do Brasil se caracteriza pela fusão de etnias e culturas, pela contínua ocupação de diferentes regiões geográficas, pela diversidade de fisionomias e paisagens e também pela multiplicidade de visões sobre miscigenação em sentido amplo, algumas ainda presas à desinformação e ao preconceito. Esse caldo de cultura muitas vezes gera atritos e conflitos em casa, na rua, no trabalho e na escola. Para preencher o vazio da desinformação e corrigir a distorção de valores que encerra, o Ministro da Educação publica este Superando o Racismo na Escola" (in Munanga, 2005, p. 7 - grifos meus).

O ministro Paulo Renato fala sobre o país misturado, no "caldo de cultura", enfatizando um país miscigenado.

No ano seguinte, em prefácio à segunda edição, o presidente Fernando Henrique Cardoso dá continuidade à fala do ministro:

"Racismo e ignorância caminham sempre de mãos dadas. Os estereótipos e as idéias preconcebidas vicejam se está ausente a informação, se falta o diálogo aberto, arejado, transparente" e continua: "É obrigação do Estado a proteção das manifestações culturais das culturas populares, indígenas e afro-brasileiras, bem como dos demais grupos participantes do nosso processo civilizatório. Essa obrigação deve refletir-se também na educação". Também diz que: "A sociedade brasileira tem razões de sobra para se preocupar com estas questões. Nossa formação nacional tem como característica peculiar a convivência e a mescla de diversas etnias e diferenças raciais". Termina informando que: "A superação do racismo ainda presente em nossa sociedade é um imperativo. É uma necessidade moral e uma tarefa política de primeira grandeza. E a educação é um dos terrenos decisivos para que sejamos vitoriosos nesse esforço" (in Munanga, 2005, pp. 9-10).

O presidente Fernando Henrique é ambíguo na sua mensagem: embora fale de

\footnotetext{
As Diretrizes foram exaradas em documento aprovado pelo Conselho Nacional de Educacão através do Parecer CP 3/2004, Processo $23001.000215 / 2002-96$ aprovado em sessão do CNE em março de 2003. De agora em diante nos referiremos a elas como Diretrizes.

8 Ver sobre isso: Horizontes Antropológicos, ano $11, n$ 23 , janeiro-junho de 2005
} 
mescla de etnias, frisa a multirracialidade da nossa sociedade. Assim, seu discurso indica que o caminho para a superação do racismo está na admissão de uma sociedade multirracial e não mais misturada.

Cinco anos depois, em pleno governo Luiz Inácio Lula da Silva, sai a terceira edição do mesmíssimo livro, dessa vez prefaciado por Ricardo Henriques, secretário de Educação Continuada, Alfabetização e Diversidade, e Eliane Cavalleiro, coordenadora geral de Diversidade e Inclusão Educacional do Ministério da Educação. Agora se fala mais de mescla, mas em "raças" distintas, num novo discurso de verdade:

“[...] a escola que superará o racismo há de ser uma escola que saiba, sobretudo, aprender e relacionar-se com o mundo de possibilidades que a sociabilidade negra criou, seja nas mais de quatro mil comunidades quilombolas conhecidas, seja na música urbana de um compositor como Martinho da Vila" (in Munanga, 2005, p. 12 , grifos meus).

Citando um dos artigos do livro, o prefaciador diz: "Os artigos de [...] convidam professores e professoras a evadir-se do mundo fechado de referências e práticas eurocêntricas em que foram (de)formados e ao qual foram confinados". E ainda: " $A$ violência racial na escola ainda não é computada como exercício de violência real". E mais adiante: “A violência racial escolar atenta contra o presente, deforma o passado e corrói o futuro" (in Munanga, 2005, pp. 12 e 13, grifos meus).

Os três prefácios reproduzidos na edição de 2005 expressam assim a velocidade da caminhada que também está presente em outras esferas da nossa história recentíssima. O discurso de verdade que vê a sociedade do "caldo de culturas" e de "fusão" ou de "mescla" parece estar sendo suplantado por outro que vê uma sociedade de "sociabilidades" negras onde existem "mais de 400 comunidades quilombolas".

O livro produzido em 1999 tem apresentação de Kabengele Munanga, que exorta o leitor a enfrentar "sem nenhum complexo de culpa [...] que somos produtos de uma educação eurocêntrica". Logo em seguida diz que

“[...] alguns professores, por falta de preparo ou por preconceitos neles introjetados, não sabem lançar mão das situações flagrantes de discriminação no espaço escolar e na sala de aula como momento pedagógico privilegiado para discutir a diversidade e conscientizar seus alunos sobre a importância e a riqueza que ela traz à nossa cultura e à nossa identidade nacional" (Munanga, 2005, p. 15).

A apresentação de Kabengele de 1999 esboça uma formulação que está presente no discurso que só será instalado por força de lei, bem mais tarde, embora já estivesse presente nos argumentos de Hasenbalg (1979) nos anos 1970.

"Não precisamos ser profetas para compreender que o preconceito incutido na cabeça do professor [...] somando-se ao conteúdo preconceituoso dos livros e materiais didáticos e às relações preconceituosas entre alunos de diferentes ascendências étnicoraciais, sociais e outras, desestimulam o aluno negro e prejudicam seu aprendizado. O que explica o coeficiente de repetência e evasão escolar altamente elevado do alunado negro, comparativamente ao do alunado branco" (Munanga, 2005, p. 16).

O livro contém artigos de muitos intelectuais que cinco anos mais tarde iriam liderar os discursos que enfatizam as cotas como o caminho para enfrentar essas desigualdades na educação brasileira. Mas não se fala de ações afirmativas e a expressão "cotas" também não aparece nos textos. Como exemplo cito o trabalho de Petronilha Beatriz Gonçalves da Silva, que afirma ser necessário "o estudo das africanidades com o propósito de que os currículos escolares, em todos os níveis de ensino":

- valorizem igualmente as diferentes e diversificadas raízes das identidades dos 
distintos grupos que constituem o povo brasileiro;

- busquem compreender e ensinem a respeitar diferentes modos de ser, viver, conviver e pensar;

- discutam as relações étnicas, no Brasil, e analisem a perversidade da assim designada "democracia racial";

- situem histórica e socialmente as produções e/ou influência africana no Brasil e proponham instrumentos para que sejam analisadas e criticamente valorizadas (in Munanga, 2005, p. 157).

Menos de cinco anos depois de ter escrito esse artigo para o livro organizado por Kabengele Munanga, Petronilha Beatriz Gonçalves da Silva foi relatora do processo ${ }^{9}$ que estabeleceu as Diretrizes Curriculares para a Educação das Relações Étnico-Raciais e para o Ensino de História e Cultura Afro-Brasileira.

\section{QUE DIZEM AS NOVAS}

\section{DIRETRIZES CURRICULARES PARA} A EDUCAÇ̃̃O DAS RELAÇ̃̃ES ÉTNICO-RACIAIS E PARA 0 ENSINO DE HISTÓRIA E CULTURA AFRO-BRASILEIRA

O parecer que embasa a nova lei é um documento e um exemplo de como oEstado propõe exacerbar a racialização da sociedade em vez de debelá-la como diz Peter Fry (2005). Embora reconheçam que "raça" é uma construção social, quase todas as propostas, em vez de combater a crença em "raças" e o racismo, fazem o contrário:

"É importante destacar que se entende por raça a construção forjada nas tensas relações entre brancos e negros, muitas vezes simuladas como harmoniosas, nada tendo a ver com o conceito biológico de raça cunhado no século XVIII e hoje sobejamente superado. Cabe esclarecer que o termo 'raça' é utilizado com frequiência nas relações sociais brasileiras para informar como determinadas características físicas, como cor de pele, tipo de cabelo, entre outras, influenciam, interferem e até mesmo determinam o destino e o lugar social dos sujeitos no interior da sociedade brasileira. Contudo, o termo ganhou novo significado com o Movimento Negro que, em várias situações, o utiliza com o sentido político de valorização do legado deixado pelos africanos" (Brasil, 2005, p. 10).

O documento, depois de afirmar que a “consciência política e histórica da diversidade deve conduzir à igualdade básica de pessoa humana como sujeito de direitos", constata que o "fortalecimento de identidades e de direitos deve conduzir para [...] o esclarecimento a respeito de equívocos quanto a uma identidade humana universal". Mesmo afirmando a luta contra a discriminação racial e o preconceito, o documento instiga as escolas a imaginar e produzir um país não da mistura, mas como uma sociedade composta de "raças" e "grupos étnicos" separados, como bem frisou Fry (2005, pp. 346-7).

Como diz o parecer, a sociedade brasileira é formada "por pessoas que pertencem a grupos étnico-raciais distintos, que possuem cultura e história próprias, igualmente valiosas e que em conjunto constroem, na nação brasileira, a sua história”. Dá ainda uma dimensão extrema a essa diversidade entre "grupos étnicos":

“[...] o Brasil, país multiétnico e pluricultural, de organizações escolares em que todos se vejam incluídos, em que lhes seja garantido o direito de aprender e de ampliar conhecimentos, sem ser obrigados a negar a si mesmos, ao grupo étnico/racial a que pertencem, a adotar costumes, idéias, comportamentos que lhes são adversos. E estes certamente serão indicadores da qualidade da educação que estará sendo oferecida pelos estabelecimentos de ensino de diferentes níveis" (Brasil, 2005, p. 18).
9 Osoutros membros da comissão foram Carlos Roberto de Jamil Cury, Francisca Novantino Pinto de Ângelo e Marilia Ancona López, e o conselheiro-presidente José Carlos Almeida da Silva. 
As Diretrizes encorajam uma educação ou reeducação que faça dos cidadãos pessoas orgulhosas de seu "pertencimento étnico-racial”. Assim, é preciso valorizar a “diversidade" a fim de superar as desigualdades étnico-raciais.

"Políticas de reparações e de reconhecimento formarão programas de ações afirmativas, isto é, conjuntos de ações políticas dirigidas à correção de desigualdades raciais e sociais, orientadas para oferta de tratamento diferenciado com vistas a corrigir desvantagens e marginalização criadas e mantidas por estrutura social excludente $\mathrm{e}$ discriminatória. Ações afirmativas atendem ao determinado pelo Programa Nacional de Direitos Humanos, bem como a compromissos internacionais assumidos pelo Brasil, com o objetivo de combate ao racismo e a discriminações, tais como: a Convenção da Unesco de 1960, direcionada ao combate ao racismo em todas as formas de ensino, bem como a Conferência Mundial de Combate ao Racismo, Discriminação Racial, Xenofobia e Intolerância Correlata de 2001" (Brasil, 2005, p. 12).

Afirmam ainda as Diretrizes que os movimentos negros têm comprovado a dura experiência de "fingir ser o que não é para ser reconhecido [...] de quão dolorosa pode ser a experiência de deixar-se assimilar por uma visão de mundo que pretende impor-se como superior e por isso universal e que os obriga a negarem a tradição do seu povo" (Brasil, 2005, p. 11).

Para finalizar, uma espécie de profecia ameaçadora:

10 Processo que também já começou porque o Ministério da Educação iniciou um curso de formação de professores. MEC também promoveu ao longo do ano de 2005 fóruns de discussão sobre as Diretrizes chamando representantes dos movimentos negros, sociólogos, educadores e antropólogos para o debate. Há também iniciativas de universidades que estão oferecendo cursos de formação de professores, como a Universidade Federa de São Carlos. ço da marginalização e da desigualdade impostas a outros. E então decidir que sociedade queremos construir daqui para frente" (Brasil, 2005, p. 11).

Essas Diretrizes foram criticadas por José Roberto Pinto de Góes, que se espantou com as expressões utilizadas no documento: "De que revanche estão falando? E o que dizer dessa história de fazer emergir dores e medos?" (Góes, 2004).

O que se pode apreender da leitura dessa lei estabelecida pelo Conselho Nacional de Educação é que ela apresenta um Brasil radicalmente distinto daquele dos textos anteriores, que falam de mistura, de caldo de cultura, etc. e representam uma visão alinhada aos movimentos negros que são citados nominalmente inúmeras vezes ao longo do texto.

As Diretrizes ainda arrolam em seu parecer uma lista de atividades a serem desenvolvidas pelas instituições de ensino, entre elas o diálogo com estudos que analisam e criticam essas realidades bem como com grupos do Movimento Negro. Listam tambémuma série de personalidades negras nacionais e estrangeiras que devem ser estudadas e ainda se referem à necessidade de reconhecimento da "matriz africana" ou temas que dizem respeito à população negra, como a anemia falciforme e a "problemática da pressão alta”. Finalmente afirmam:

"[...] cabe lembrar que preto é um dos quesitos utilizados pelo IBGE para classificar, ao lado dos outros - branco, pardo, indígena -, a cor da população brasileira. Pesquisadores de diferentes áreas, inclusive da educação, para fins de seus estudos, agregam dados relativos a pretos e pardos sob a categoria negros, já que ambos reúnem, conforme alerta o Movimento Negro, aqueles que reconhecem sua ascendência africana” (Brasil, 2005, p. 15).

Uma das condições para a implantação das Diretrizes refere-se à qualificação de professores que "promovam a reeducação das relações entre diferentes grupos étnicoraciais" ${ }^{10}$. OMinistério da Educação, assim, 
a partir das Diretrizes, lançou as bases para uma política do que tem sido chamado de "educação das relações étnico-raciais".

Como uma pedagogia de cunho racial, ainda lança mão da ciência justificando o uso da nova categoria "negro" a partir do uso que é feito por "pesquisadores de diferentes áreas".

As Diretrizes, diferentemente dos livros didáticos que estão nas bibliotecas de muitas escolas por nós pesquisadas, não descrevem nossa mistura e, ao afirmarem a universalidade da espécie humana, frisam muito mais as diferenças e divergências entre etnicidades, culturas e "raças".

Mas essas Diretrizes não vieram apenas para ficar no papel. Elas estão sendo aplicadas em algumas das 21 escolas do nosso universo de estudo, e, entre essas escolhemos um caso para observar e descrever o seu processo de implantação. É uma escola de ensino médio do bairro de Irajá, na Zona

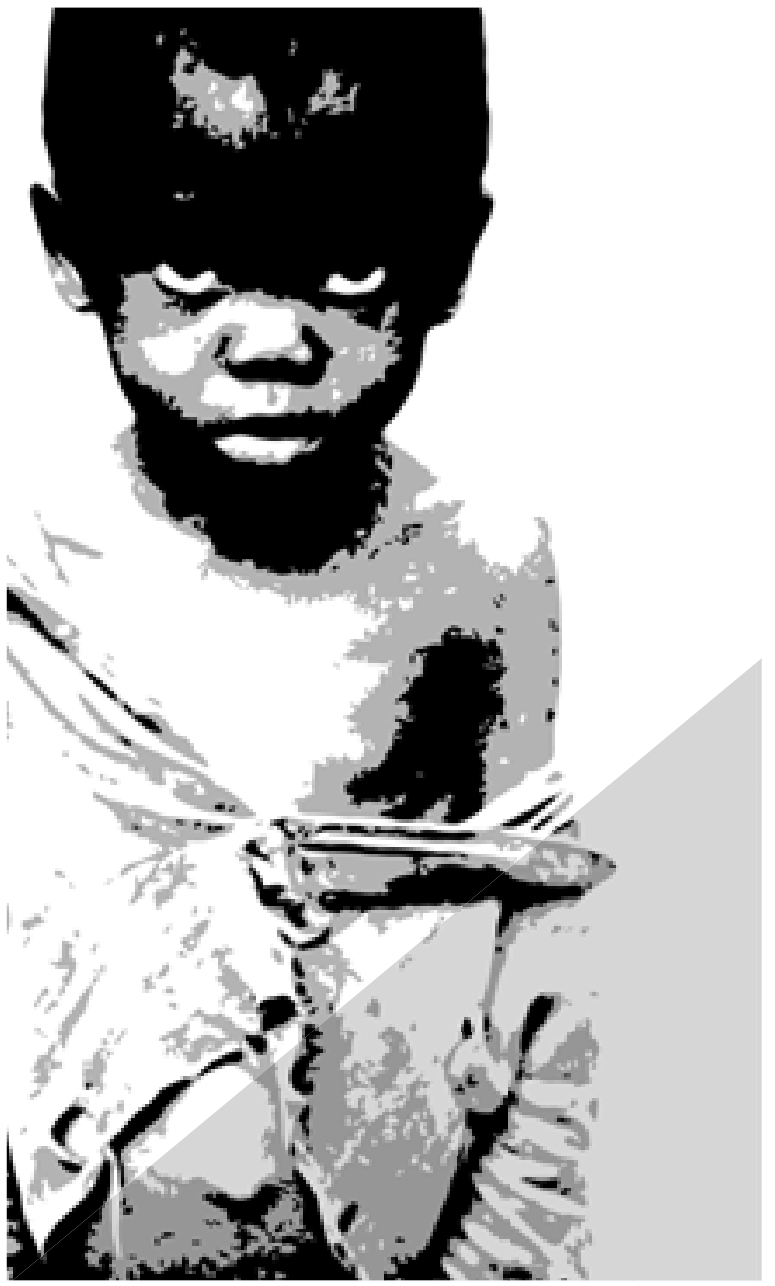

Norte do Rio de Janeiro. Cerca de 1.029 estudantes frequientam essa escola, que fica em um prédio moderno, com uma bela quadra de esportes, um terreno amplo e uma boa biblioteca, como são todos Cieps planejados por Oscar Niemeyer durante o primeiro governo Brizola e na gestão de Darcy Ribeiro à frente da Secretaria de Educação. Ainda não podemos afirmar com exatidão o perfil socioeconômico dos estudantes dessa escola porque só agora estamos aplicando os questionários em uma amostra significativa. No entanto, podemos dizer que é uma escola típica de bairros pobres da Zona Norte da cidade. Nela estudam jovens que em sua maioria são primeira geração de estudantes que chegam ao ensino médio em suas famílias. As mães freqüentaram a escola mais tempo que os pais e, em sua maioria, têm até a quarta série do ensino fundamental. A escola tem uma alta taxa de distorção série/ idade e está classificada no nível mais baixo da pontuação do Programa Nova Escola. Também participa do Programa Sucesso Escolar ${ }^{11}$, que foi desenhado para melhorar a atuação dos estudantes dessas escolas de baixo desempenho. No entanto, a escola foi recentemente reformada e é considerada uma ótima escola pelos pais e vizinhança. Ao lado desse Ciep há outro em péssimas condições físicas, e que é tido como uma escola ruim pela comunidade ${ }^{12}$.

Ludmila Fernandes de Freitas, pesquisadora bolsista da Fundação Ford no projeto "Acompanhando as ações afirmativas no ensino superior”, foi responsável pela pesquisa de campo nessa escola estudada. $\mathrm{O}$ estudo de caso foi iniciado em março de $2005^{13}$.

Há várias experiências de aplicação dessas Diretrizes sendo feitas em outras escolas e estados da federação, mas vamos nos deter nesse caso com a finalidade de revelar a estrutura e os princípios que a organizam. Escolhemos essa escola entre as 21 pesquisadas porque foi uma das primeiras escolas da rede a aplicar as Diretrizes citadas e por ter seguido de perto as recomendações feitas nos fóruns promovidos pelo Ministério da Educação no sentido de orientar os professores ${ }^{14}$.
11 Sucesso Escolar é um outro programa implantado em 2004 pela Secretaria de Educação do Estado para melhorar a proficiência dos estudantes em matemática e português. Os alunos que participam desse programa estão na iminência de ser reprovados e, em geral, são considerados maus alunos.

12 As escolas são avaliadas pelo Estado, pelo governo federa e por agências internacionais mas são também avaliadas pela comunidade. Em cada bairro há boas e más escolas segundo os moradores, pais, professores, etc. Sobre essa questão estão trabalhando outras pesquisadoras da equipe, Encarnação (2005) e Galeno (2005).

$13 \mathrm{~A}$ pesquisadora participa das reuniões semanais de pesquisa realizadas desde agosto de 2004 nas quais a equipe é treinada passo a passo. Além de percorrer uma leitura especializada sobre educação os pesquisadores leram e debateram clássicos da pesquisa antropológica. Foram ainda discutidas as formas com que as entrevistas e histórias de vida deveriam ser conduzidas. Elaborou-se um roteiro de entre vistas com estudantes e professores, diretores e orientadores pedagógicos. Decidiu-se que cada pesquisador escolheria um ou dois casos entre professores e estudantes, que deveriam ser entrevistados a cada ano sobre os mesmos temas para que pudéssemos fazer um follow-up desses personagens ao longo da pesquisa. Além disso, os pesquisadores participam das atividades da escola e ainda seguem de perto alguns eventos promovidos pelo Ministério da Educação e pela Secretaria Estadual de Educação. Todos enviam semanalmente sua etnografia para um banco de dados para ser lida e analisada pela equipe.

14 Assistimos a alguns desses fóruns promovidos pela Secretaria de Educação Continuada, Alfabetização e Diversidade, chefiada pelo economista Ricardo Henriques. Nesses fóruns, diretores, professores $e$ coordenadores pedagógicos são orientados através de palestras com representantes dos movimentos negros e es pecialistas. Esses fóruns são também paradigmáticos e explicitam essa pedagogia racial de conversão identitária Não trataremos deles no âmbito deste artigo para não nos alongarmos ainda mais. 


\section{UM MERGULHO NO UNIVERSO ESCOLAR}

A biblioteca da escola constitui-se em importante local onde pudemos, através de uma pesquisa nos livros de história do Brasil lá existentes, observar se os mesmos vêm respondendo a essa nova pedagogia reclamada pelo referido parecer. A biblioteca possui um acervo relativamente grande se comparado ao de outras escolas da rede. O acervo é relativamento rico, com as últimas edições de livros de Gilberto Freyre, Vitor Nunes Leal, Roberto DaMatta, Caio Prado Junior, Darcy Ribeiro, Celso Furtado, Luís da Câmara Cascudo, José Murilo de Carvalho, Sérgio Buarque de Holanda, Nelson Werneck Sodré, sem contar Sergio Paulo Rouanet com o seu As Razões do Iluminismo. É claro que lá estão José de Alencar, Machado de Assis, Graciliano Ramos e muitos outros da nossa literatura. Ao longo do ano a diretora anunciou a compra de alguns novos livros sobre os temas ${ }^{15}$ propostos pelas Diretrizes.

Os livros de ensino médio de história do Brasil nessa biblioteca são, em sua maioria, da década de $1980^{16}$. Falam dos sucessivos "cruzamentos raciais" que deram origem à formação do povo brasileiro: "Quando falamos em origem do homem brasileiro nos referimos ao brasileiro nato, isto é, ao indivíduo que nasce no Brasil e que é resultante de intensa miscigenação" (Lucci, 1984, p. 73). Também descrevem os "elementos" formadores da etnia brasileira e suas contribuições culturais na comida, hábitos, objetos, música, religião e vocabulário. Segundo esses manuais de história, os elementos étnicos foram o índio, o negro e o branco (português) e, posteriormente, os imigrantes. Os autores dos livros didáticos ressaltam também que a colonização do Brasil propiciou o cruzamento entre os "três elementos étnicos" dando origem aos seguintes tipos fundamentais de mestiços: caboclo ou mameluco (cruzamento entre o branco eo índio), mulato (cruzamento entre o negro e o branco) e cafuzo (cruzamento entre o índio e o negro): "Rompendo as barreiras das diferenças raciais, entrecruzando-se a cada nova geração, realizaram eles o mais completo fenômeno da miscigenação racial e aculturação que a terra conhece. Séculos mais tarde os imigrantes trouxeram sua contribuição ao já intenso caldeamento" (Duarte, 1982, p. 93).

Em um deles discute-se a idéia de "raça":

"Sabe-se apenas que todos os homens pertencem à mesma espécie - Homo sapiens . Mesmo a divisão clássica em raça branca, negra e amarela não pode persistir, porque os grupos que se classificam nesses três grandes ramos não apresentam uniformidade suficiente para se fazer uma catalogação satisfatória dos seus característicos básicos. Não se sabe tampouco se essas três variantes têm uma origem comum, ou se cada uma resulta da evolução autônoma de seres pré-humanos diferentes" (Carvalho, 1970, pp. 100-1).

Saindo da biblioteca e examinando um dos livros utilizados pela rede de ensino estadual em 2005(Cabrini, Catelli \& Montellato, 2005a; 2005b), não vimos aquela antiga cronologia de acontecimentos tão utilizada como metodologia para o ensino da história nem tampouco o nosso mito de origem das três raças. Agora dá-se maior destaque à história da África e à "cultura africana". Também se descrevem as comunidades de quilombos como espaços de "resistência negra”. Mas há uma diferença mais importante na forma de contar a nossa história. A sociedade brasileira é descrita como o lugar do desencontro entre culturas:

"Mas o que acontece quando diferentes povos com distintos modos de vida se encontram? Com freqüência um desencontro. Principalmente quando um deles se julga no direito de impor sua cultura aos outros ignorando outros conhecimentos, saberes e 'verdades'.

Ao longo do tempo, muitos povos consideraram a sua própria cultura a medida para todas as outras. Assim, movidos pelo 


\section{HISTÓRIA DA IMPLANTAÇÃO DO PROJETO}

Na escola estudada as novas Diretrizes estão sendo trabalhadas em forma de projeto. O projeto-piloto chama-se "Mitos e tabus na cultura afro-brasileira”. Quatro professoras $^{17}$ trabalham diariamente no projeto através das atividades complementares (Aticom), como Educação Artística e História, e com todas as turmas do ensino médio. Segundo os diretores, este ano o Aticom privilegia a matéria História e essa nova “disciplina” é "tratada como conteúdo programático da escola e não como uma cadeira à parte". No entanto, o projeto ainda não está incluído no Projeto Político Pedagógico (PPP) da escola, o que será feito no próximo ano, de acordo com a diretora. Segundo a professora Lídia, uma das promotoras do projeto na escola, os professores envolvidos fizeram um acordocom a direção para que os alunos pensassem que a frequiência às aulas era obrigatória. Lídia considera a presença de $40 \%$ de alunos em sala um número bem relevante para uma escola que possui 26 turmas, 13 nas quais ela trabalha. "Se você pegar esse universo de alunos e pegar $40 \%$ eu acho que a gente está conseguindo um trabalho de peso. Não de conseguir atingir o objetivo, mas de fazer a abordagem num número bem relevante", diz a professora.

Ainda segundo a diretora dessa escola pesquisada, o Ministério da Educação não obrigou a trabalhar com as Diretrizes nesse ano. Apesar da não-obrigatoriedade, o último Conselho de Classe da escola, no ano de 2004, já tinha discutido a sua implantação. Quando perguntamos sobre a recepção desse novo parecer pelos demais professores, Laura, outra das professoras responsáveis pelo projeto, disse que eles ficaram calados, não emitindo opiniões nem contra nem a favor.

As duas principais professoras responsáveis pela aplicação das Diretrizes na escola, Lídia e Rosângela, fizeram especialização/ pós-graduação em História da África em

17 Os nomes das professoras são fictícios. 
uma universidade particular e chegaram em 2005 à escola pesquisada.

Para a professora Lídia, a noção que os estudantes têm da África precisa ser modificada, pois o aluno não se sente valorizado como descendente africano por causa da escravidão. "Esse estigma de escravidão continua depois que a escravidão acaba porque o negro ainda é lembrado, vinculado à escravidão", diz a professora. Por isso nessas aulas são discutidos temas que possam fazê-los pensar o negro de outra forma. As professoras estão trabalhando com materiais elaborados por elas porque não encontraram nenhum livro didático que considerassem bom.

\section{COMO ESTÃO SENDO APRESENTADAS AS NOVAS DIRETRIZES}

A primeira etapa do projeto foi o Ciclo de Informações que aconteceu no auditório da escola no dia 12 de maio de 2005. Nele estiveram presentes dois palestrantes - um membro do Movimento Negro e uma representante da Secretaria Estadual de Cultura-, que falaram sobre ações afirmativas (cotas, principalmente) e também sobre a presença do negro nos livros didáticos.

Nesse dia os trabalhos dos alunos relativos ao tema também estavam dispostos sobre as mesas e fixados nas paredes do corredor da escola. Máscaras africanas, indumentária africana, pequenos objetos religiosos, além de outros trabalhos feitos com a técnica do pontilhismo estavam também expostos juntamente com poesias e raps feitos pelos alunos. Eles expunham as várias formas de preconceito tais como: racial, contra gordos, magros, feios, pessoas mais velhas que voltavam a estudar, etc.

Lídia destacou o fato de a data marcada para o Ciclo de Informações - dia 12 de maio - "não ser à toa" e disse ser esse um “dia de reflexão", pois o dia seguinte era
13 de maio. Também explicou que o que ali viria a acontecer não era uma palestra, mas um Ciclo de Informações, diferenciando-se pela possibilidade de serem feitas perguntas ao final.

Datas significativas, como 20 de novembro (Dia Nacional da Consciência Negra) e 21 de março (dia Internacional de Luta pela Eliminação da Discriminação Racial), deverão ser devidamente assinaladas. "O 13 de maio, Dia Nacional de Denúncia contra o Racismo, será tratado como o dia de denúncia das repercussões das políticas de eliminação física e simbólica da população afro-brasileira no pós-abolição, e de divulgação dos significados da Lei Áurea para os negros", como determinam as Diretrizes (Brasil, 2005, p. 21), o que demonstra que as professoras as estão seguindo à risca.

A representante para assuntos afro-brasileiros da Secretaria Estadual de Cultura falou sobre a questão da modificação que vem ocorrendo nos livros didáticos tanto em relação à introdução de uma maior presença de personagens negros como também da história da África.

$\mathrm{O}$ representante do Movimento $\mathrm{Ne}$ gro discorreu sobre as ações afirmativas demonstrando que elas são necessárias porque vieram para corrigir uma distorção ocasionada peloracismo, exemplificando-a com a seguinte metáfora: um corredor que inicia a corrida acorrentado enquanto o outro corre livremente nunca poderá chegar ao mesmo tempo no final da corrida. Os negros foram assim acorrentados e para corrigir essa defasagem, esse atraso, é preciso que lhes sejam dadas condições especiais para que possam chegar ao final com as mesmas oportunidades. Ou seja, uma aula sobre o pressuposto da democracia liberal americana, que propõe tratar desigualmente os desiguais, invertendo assim a nossa tradição republicana de tratar todos como iguais.

Todos os anos os alunos apresentam trabalhos em uma Feira Cultural Interdisciplinar. O tema da feira em 2005 foi "Brasil e Brasis: uma grande diversidade" (grifo meu). Como diz o folheto explicativo distribuído na escola, "A Feira Cultural Interdisciplinar de 2005 está relacionada 
ao Projeto Político Pedagógico da Escola, o qual procura discutir a brasilidade a partir da influência africana no Brasil [grifos meus]. Partimos do pressuposto de que o Brasil é multicultural e apresenta uma grande diversidade social, econômica e natural". Pensando assim, uma Feira Cultural Interdisciplinar sobre o país foi o caminho encontrado pelo corpo pedagógico, "pois levaria os alunos a entrar em contato com nossas particularidades e conhecer a realidade em que estamos inseridos enquanto sujeito social".

As professoras responsáveis pelo projeto afirmam que muitas escolas envolvidas reconhecem a dificuldade de aceitação por parte de gestores das unidades escolares (sejam elas particulares ou públicas), coordenação, orientadores pedagógicos, assim como demais professores, até mesmo em saber que essas novas Diretrizes existem e são obrigatórias.

Como expôs a professora Lídia, o projeto está sendo implementado através de “conflitos e negociações". Ainda segundo ela, "é muito complicado você fazer o aluno se reconhecer negro enquanto que é tudo que ele está querendo esquecer. Nós estamos com o espelho na frente dele dizendo: você é negro! E é exatamente o que ele não quer, se ver como negro. Os que têm a cútis, a pele, um pouco mais clara se acham moreninhos, mulatos, marrom-bombons". Para ela a maior dificuldade para a implantação do projeto é em relação ao aluno: “A gente está negociando com eles a partir do momento que a gente está mostrando uma realidade que eles não querem ver ou não conhecem. Ou, quando não conhecem, não interiorizam". No entanto, como é um projeto-piloto, a professora acredita que essa é uma dificuldade que pode ser ultrapassada. Segundo ela, daqui a uns dois ou três anos, quando esses alunos alcançarem o terceiro ano, vai haver maior “conscientização" por parte deles. "Através desse processo de reconstrução da identidade, saberão o que significa ser mulato no Brasil, o que significa ser 'crioulo', o que é que é o 'pardo', que política é essa de desigualdade, o que é o mito da democracia racial."
Além dos ciclos de informação, as professoras passam trabalhos sobre as influências da cultura afro-brasileira. Os alunos podem escolher temas como a comida, a dança, a religião, o vocabulário, etc.

\section{COMO ESTÃO SENDO RECEBIDAS AS ATIVIDADES"}

Conversando com alguns alunos que participaram dessas atividades pudemos verificar que eles não acham que a matéria seja obrigatória. Sabem que os trabalhos contam ponto para a matéria de História e sabem também que as faltas da Aticom não são contabilizadas.

Segundo esses alunos, uma das professoras, durante as aulas, passa filmes e discute sobre o estereótipo do negroe sobre música. Ela também pediu que cada estudante fizesse a árvore genealógica de sua família, o que auxiliaria no censo de cor que foi feito na escola ${ }^{19}$. Outra aluna, também do terceiro ano, disse que as aulas eram chatas, que a professora "só fala de negro" e "todo mundo já tá de saco cheio disso". Suélen, que estuda no turno da manhã, reclamou também que a professora não escrevia no quadro $^{20}$, e ficava quase uma hora explicando. A turma do terceiro ano, como disse uma das alunas, teve inclusive a idéia de fazer um abaixo-assinado para tirar a professora da Aticom, pois "está todo mundo cansado porque ela só fala de negro”. Essa mesma aluna disse que uma vez a professora deu como exemplo três alunas da sala ao falar da dificuldade de conseguir um emprego numa loja no shopping. Apontou para as três meninas ("uma mais escura, uma média e uma mais clara") e disse que por causa da cor dificilmente as mais escuras seriam escolhidas para o emprego por mais experiência que tivessem.

No entanto, também há alunos que gostam da aula, apesar de discordarem da maneira como ela é dada. O aluno Vinícius, do terceiro ano, turno da manhã, disse gostar da aula porque ela promove discussão,
$18 \mathrm{~A}$ pesquisadora Ludmila Fernandes de Freitas, aluna de graduação do curso de Ciências Sociais do IFCS/UFR, fazo trabalho de campo nessa escola e, como já dissemos, produziu essa etnografia. Participou dessas aulas e de atividades promovidas pelas professoras responsáveis. Os alunos foram entrevistados tanto nos intervalos das aulas, quanto nas atividades extraclasse e no recreio. Todos os alunos entrevistados eram estudantes do ensino médio dos turnos da manhã e da tarde. A escola estudada não tem turno noturno como outras escolas da rede.

190 censo escolar de 2005 incluiu pela primeira vez o quesito cor, 0 quefezcom que todos os alunos tivessem que se autoclassificar segundo as categorias do Censo Demográfico Nacional.

20 Estamos analisando também as aulas e como são dadas nessas escolas pesquisadas. Mas não vamos tratar disso neste artigo. Para uma discussão da sala de aula ver: Saerp, 2005. Aqui vamos apenas indicar que 0 mais comum nessas escolas são aulas em que os professores passam a maior parte do tempo escrevendo a matéria no quadro e esperando que os alunos copiem no caderno. Esse tipo de aula foi classificado por uma de nossas pesquisadoras (Sousa, 2005) como "aula de transcrição". Alguns estudantes preferem esse tipo de aula e muitas vezes reclamam quando isso não é feito 
mas fica indignado com quem inventou essa matéria. Para ele, ela não é coerente: "A aula é legal, mas não a forma como é dada". O aluno deu diversos exemplos sobre a mistura existente no Brasil citando sua irmã que é "loirinha", e mais branca do que ele, bem como a possibilidade de uma pessoa negra ter um filho mais claro e vice-versa. Completou sua opinião dizendo que a professora "reivindicou uma coisa que não era para reivindicar: a cor dela. Chega a um ponto que ela está discriminando ela mesma”. De tanto falar em discriminação, segundo esse aluno, a professora acaba se autodiscriminando. Esse mesmo aluno disse ter ficado constrangido nas primeiras aulas porque ele não concordava com temas como cotas para negros e preconceito racial da forma que eram colocados pela professora. "Não concordo com as instituições levantarem coisas para os negros." Uma frase da professora que marcou Vinícius foi: "Negro não é cor, é raça!".

Um outro aluno do terceiro ano diurno disse ver a professora como afro-brasileira. E se apressou em dizer que não tem nenhum preconceito porque também se considera afro-brasileiro. Perguntado se estava gostando dessas aulas, disse: "mais ou menos". Sua crítica refere-se ao posicionamento da professora, ao jeito pelo qual ela se expressa durante as aulas: "Ela fala de um jeito que parece que se alguém falar algo contra ela é capaz de dar um soco. Ela defende os afro-brasileiros de um jeito que parece que os brancos é que são os escravos. Ela fala de um jeito como se estivesse ofendendo ela"; "Ela explicou que o afro-brasileiro é aquela pessoa mais escura de pele e também explicou sobre a árvore genealógica, porque tem sempre uma pessoa na nossa família que é afro-brasileira".

Propusemos uma conversa com sete alunos do primeiro ano do turno da manhã e pedimos que cada um deles resumisse em uma palavra o que significa "cultura afrobrasileira”. De início eles demoraram a responder, mas logo disseram: "consciência" ("saber que isso é importante"), "respeito", “vida”, “dignidade”, “injustiça”. Pedimos então que resumissem em uma palavra o que é "afro-brasileiro". Então apareceram palavras como "origem", “dignidade", "normal", "honesto" e "humildade".

Dois outros alunos que participam do Programa Sucesso Escolar também não gostam das aulas de cultura afro-brasileira. Não assistem a elas. Fizemos as mesmas perguntas a esses alunos quando estávamos observando uma aula do Programa Sucesso Escolar pedindo que resumissem em uma palavra oque é "cultura afro-brasileira". Os alunos logo citaram as influências: "África, africanos, comidas,..."; “culturas que os negros trouxeram para o Brasil”. Sobre "afro-brasileiro" o aluno respondeu como se estivesse nos perguntando e duvidando de sua própria resposta: "Uma pessoa negra?”. Já o outro disse: “O modo de agir é diferente, candomblé, comidas típicas, da Bahia, olodum ...".

Para as professoras responsáveis pela aplicação das Diretrizes nessa escola, os alunos dizem tais coisas porque resistem. Elas consideram esse posicionamento contrário dos alunos como falta de "educação" e de "consciência". Sobre isso Lídia disse o seguinte:

"Numa família que já tenha essa auto-estima, ela vai criar o seu filho dentro da negritude eé muito mais fácil. Alunos ligados a algum tipo de movimento como hip-hop ou bandas ligadas a algum tipo de movimento negro assimilam melhor. Eles acham muito legal o que a gente está tratando; em contrapartida você tem um outro grupo que eu chamo de 'grupo de esconde' é o 'grupo do Michael Jackson’. Estou me vestindo de fantasma, estou ficando ridicularizado mas é melhor do que ser negro”.

Também vêem essa mesma dificuldade por parte dos outros professores, que não se interessaram muito em contribuir com o debate em questão. Segundo Lídia, “o que acontece com o professor é o mesmo que acontece com o aluno. Ele está sendo reprodutor de estereótipo. Ele também está reproduzindo tudo aquilo que nós também escutamos e aprendemos na sala de aula. Então, se ele aprendeu errado, está repro- 
duzindo errado. Então a gente tem que construir não só para o aluno, mas também para o próprio professor'.

\section{O QUE DIZEM OS PROFESSORES}

Confirmando o que disse Lídia sobre o não envolvimento de outros professores no projeto, assistimos a um fato relevante no dia do Conselho de Classe do segundo bimestre. Lídia propôs que cada professor trabalhasse com a inserção das novas Diretrizes em sua disciplina, enfatizando que esta é a primeira escola do estado com esse projeto: "Precisamos que a escola toda fale o mesmo idioma".Apenas duas professoras, de português e literatura, se manifestaram, lembrando da possibilidade de auxiliarem na discussão trazendo a influência de escritores negros na literatura brasileira, como Machado de Assis, Cruz e Sousa, Luís Gama, etc.

No terceiro Conselho de Classe a professora responsável pelo projeto das Diretrizes Curriculares na escola propôs que os alunos fizessem suas apresentações dispostos em forma de uma roda, "porque esse é o princípio da sociedade africana: a coletividade. Por isso as apresentações terão essa noção de coletividade". No meio da conversa, em tom sereno, uma professora disse: "Não interessa a cor, mas o respeito de uns com os outros”. E completou: “[...] todos nós somos humanos, filhos do mesmo pai: Deus. Seria melhor juntar todos". Pouco depois uma professora de português, que é evangélica, posicionou-se contra a idéia da disposição da roda. Disse que, se assim fosse feito, não participaria do projeto. Lídia e Rosângela tentaram então explicar por várias vezes que aquela "roda" não era "roda de ponto" ${ }^{21}$, mas uma "influência da cultura afro-brasileira”. Não satisfeita, a professora pareceu não prestar muita atenção na explicação. Outros professores comentavam paralelamente sobre esse “conflito" de opiniões, como o professor de sociologia, que citou o fato de a religião ser uma das partes da cultura.
Noentanto, muitos professores acataram o projeto das Diretrizes e estão fazendo esforços para unir-se às professoras responsáveis em incluir suas disciplinas nas atividades propostas.

\section{SOBRE A RELAÇ̃̃O DAS DIRETRIZES COM AS AÇÕES AFIRMATIVAS}

O parecer que embasa as Diretrizes, como foi dito, "procura oferecer uma resposta, entre outras, na área da educação, à demanda da população afrodescendente, no sentido de políticas de ações afirmativas, isto é, de políticas de reparações, e de reconhecimento e valorização de sua história, cultura, identidade" (Brasil, 2005, p. 10).

Como já dissemos logo no início deste trabalho, no final de 2004 fizemos um préteste com 179 questionários, que foram respondidos por alunos do primeiro ano do ensino médio. Perguntados sobre as cotas para negros, a maioria dos respondentes (51\%) não concordou com tal política. Alguns disseram que, apesar de não concordarem, aproveitariam a oportunidade por serem negros ou pardos. Um aluno do terceiro ano, quando perguntado por sua cor e pelas cotas, respondeu: "Eu acho chato esse negócio da cor, mas isso da pessoa ter pouco dinheiro e ser deficiente eu acho legal. Independente da cor ou não a pessoa é inteligente". O aluno se definiu como negro e disse que apesar de não concordar com as cotas para negros ele participaria delas porque, "já que tem essa política da cor, vou aproveitar".

Pudemos perceber melhor esse posicionamento dos alunos em relação à política de cotas quando da presença de alguns deles (a maioria, do terceiro ano) no Ciclo de Informações. Nas perguntas referidas ao palestrante, os alunos pareciam contrários ao colocarem a questão do "mérito", "do aluno que é branco e pobre ter os mesmos direitos" e se "o problema não é a educação básica de
21 "Roda de ponto" é uma expressão que designa um ritual das religiões afro-brasileiras. 
baixa qualidade". Outros posicionamentos contrários estavam fundamentados no fato de a pobreza e o ensino público de baixa qualidade não garantirem o acesso desses estudantes ao ensino superior.

Entrevistamos alunos do primeiro e terceiro anos do ensino médio sobre aspectos gerais da escola e, quando indagávamos sobre suas cores (sem fazer menção às categorias usadas pelo IBGE: branca, preta, parda, amarela ou indígena), eles preocupavam-se em responder prontamente que não eram racistas, que não tinham preconceitos. Quando a entrevista era feita com mais de um aluno ao mesmo tempo, estes tomavam como parâmetro a cor do outro (o colega) e até mesmo a de seus parentes, como os pais e os irmãos, tentando se definir em termos de gradações de cores:

"Minha cor? Acho que eu sou morena, branca. Branca. Meus pais são da minha cor também, brancos".

"Branca amarela. Minha mãe fala isso. Acho que não sou totalmente branca. Defino-me como branca porque meu olho é claro. Mas eu não acho que eu seja branca. Branco pra mim é aquela pessoa muito branca. $\mathrm{Eu}$ me defino como amarela, mas as minhas características são mais pro branco. Só a cor da pele que eu acho diferente. Meu pai e minha mãe são mais morenos do que eu. Morenos claros. Meus irmãos são da minha cor, só que mais claros do que eu".

As professoras envolvidas no projeto da implantação das Diretrizes afirmaram concordar com a política de cotas e incentivar seus alunos (principalmente os que estão no terceiro ano) a delas participar. Isso é feito através de discussões em sala sobre o assunto e mostrando as repercussões do racismo e das cotas. Só que essa mudança de postura dos alunos com relação às cotas, segundo as professoras, "faz parte da necessidade de reconstrução, formação de identidade, construção de nacionalidade". Essa falta de conhecimento (seja porque o aluno não quer ou porque não tem) gera a “baixa auto-estima do aluno”. Daí, segundo elas, a necessidade desse processo de desconstrução de identidade para a construção de uma nova identidade. "A construção da tua identidade está muito ligada a tua autoestima, valorização enquanto indivíduo, pessoa, enquanto um eu. Personalidades ou identidades estando em contato vão se fortificando, seja da forma que for, positivamente ou negativamente", disse Lídia. E continuou:

“[...] ser afro-brasileiro no Brasil é ser brasileiro porque a formação da nacionalidade brasileira foi em cima do afro muito mais do que se pensa. Ela está muito entranhada, enraizada. É muito difícil você encontrar no Brasil alguém que não seja afrodescendente. A não ser que seja um imigrante de 50 anos atrás. Quando você vê a família brasileira você é afrodescendente. Não tem como. Você querendo ou não querendo. Você não pode separar o afro-brasileiro só por um hífen. Se você é brasileiro você é afrodescendente. Você não tem outro caminho. Não há uma separação. Eu acho que o nível, o parâmetro, é generalizado".

\section{QUE DIZEM SOBRE 0 RACISMO}

Perguntados sobre o assunto do racismo, os alunos que participaram dessas aulas de Aticom não acham que ele ocorra dentro da escola. Um aluno deu o exemplo de um colega de sua sala, de nome Emerson, o qual eles chamam carinhosamente, desde o primeiro ano, de "Negão". "O chamamos assim como amigo”, explicou o aluno. $\mathrm{Ou}$ tras alunas lembraram que os meninos têm mania de pôr apelidos um nos outros como "gordo", "preto", "branco", mas não vêem isso como um preconceito ou "racismo". Vêem como "brincadeiras", formas de tratamento cordiais, amistosas.

Já as professoras envolvidas no projeto têm opiniões diferentes. Lídia disse que há muito racismo na escola:

“Há muito racismo. Pouco não. Muito. Inclusive eu fiz um trabalho com os alunos 
sobre preconceito e um aluno do segundo ano contou no trabalho que estava comendo chocolate e a colega falou que ele não poderia comer aquele chocolate porque era branco. Ele só podia comer 'diamante negro'. Eles não têm consciência, na maioria dos casos, de que estão sofrendo racismo. Eles acham que é brincadeira. Essas discriminações raciais são fruto da falta de consciência dos alunos".

Isso está interiorizado de tal forma que mesmo o aluno negro que é ofendido não sabe como agir e considera isso uma "brincadeira". Daí a importância de trabalhar a auto-estima desse aluno para que ele comece a ter essa "conscientização" que deriva de um trabalho realizado cotidianamente. Desse modo, segundo Lídia, “à medida que essa auto-estima começa a ser intensa, ele começa realmente a se sentir negro, em saber que negro é bom, é bonito, ou seja, é normal".

Sendo uma das principais propostas das novas Diretrizes o combate ao racismo e a todo e qualquer tipo de discriminação, o documento lembra que essa tarefa de reeducação das relações étnico-raciais não é exclusiva da escola. "As formas de discriminação de qualquer natureza não têm o seu nascedouro na escola, porém o racismo, as desigualdades e discriminações correntes na sociedade perpassam por ali." Contudo, "a escola tem papel preponderante para a eliminação das discriminações e para a emancipação dos grupos discriminados" (Brasil, 2005, p. 14).

\section{CONSIDERAÇ̃EES FINAIS}

Aimplantação das Diretrizes pode assim ser considerada uma outra dimensão do que Maio e Santos (2005) chamaram de “pedagogia racial" de conversão identitária. Com isso, podemos agora listar alguns dos passos que estão sendo tomados para redefinir esse universo das identidades nas escolas do estado do Rio de Janeiro.

Representantes dos movimentos negros são chamados a ser "olhos da sociedade" e "filtros" para definir quem é negro, e os professores resvalam para um discurso científico semelhante ao do "tribunal racial" estudado por Maio e Santos (2005). Os alunos que criticam o projeto de implantação são vistos como não tendo consciência, como "Michael Jackson”, e há um apelo para que todos os professores falem um mesmo "idioma racial" apesar de alguns se manifestarem contrários.

A nova proposta de idioma identitário feita pelas professoras tenta desfazer a identidade construída a partir da marca e das gradações de cor tão bem descritas por Nogueira (1985), definindo-a como falta de consciência, e o novo idioma agora deve ser aquele adotado pelos movimentos negros. No entender de uma das professoras, não há espaço para essas gradações porque, "se você tem um aluno que é mulato entre aspas, se ele for um pouquinho mais claro, ele não vai botar que é preto. Ele vai botar [no formulário do vestibular] que é branco. Por isso esse trabalho de reconstrução da identidade que nós estamos fazendo na escola é importante".

Assim, essas Diretrizes apontam um caminho para o combate ao racismo afirmando uma saída de reforço de uma identidade bipolar e étnica e o abandono das muitas maneiras relacionais de pensar a cor das pessoas, como mostra o caso relatado.

A hipótese que impulsionou a criação desse mecanismo de combate ao racismo, que está sendo implantado no Brasil e se impõe com força de lei pelo Estado visando à conversão identitária de pretos e pardos em negros, ou de morenos e uma miríade de cores em brancos e negros, foi a de que o racismo produz a disparidade nos resultados de repetência e proficiência entre brancos e negros (pretos e pardos) (Munanga, 2005).

Nos últimos anos temos visto crescer as pesquisas sobre o tema do racismo na escola com trabalhos mais etnográficos e muitos estudos de caso em que há uma relativa perplexidade diante dos dados. Fazzi (2004), em estudo em escolas do ensino fundamental em Minas Gerais, nos apresenta o que chamou de drama racial

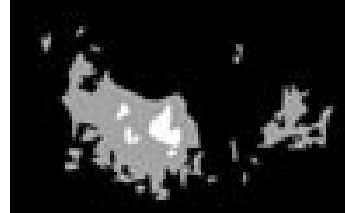

\section{$\infty$}
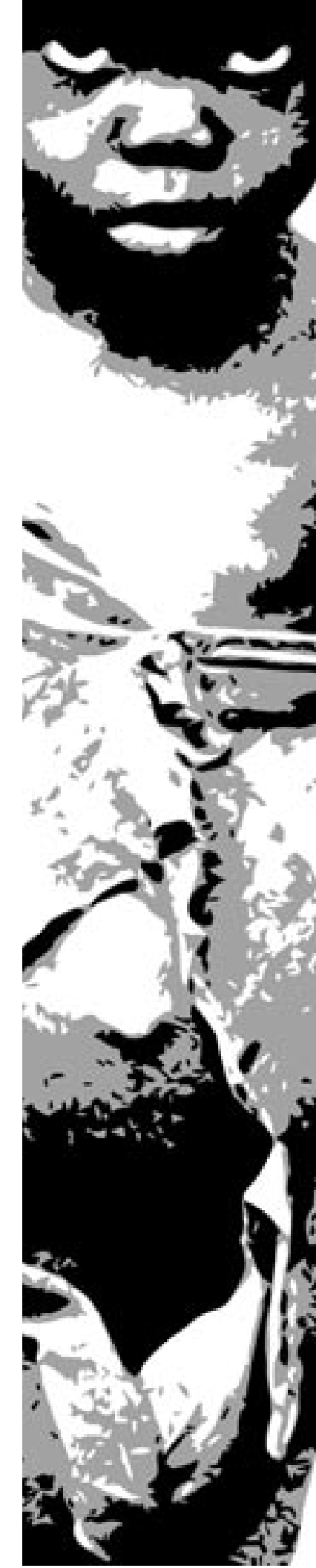
de crianças entre 6 e 8 anos que vivem a experiência dolorosa de ter que lutar para sair da identificação com a categoria preto para assim se esquivar do tratamento desigual por parte de seus pares. Outros estudos têm tentado demonstrar que o racismo, embora não percebido por professores, pais, estudantes, diretores e pessoal técnico nas escolas, é evidente nos números, como faz, por exemplo, Cavalleiro (2005). Há estudos que buscam perceber se o racismo afeta a percepção dos professores sobre a disciplina e o desempenho dos estudantes, como o de Carvalho (2005). Nesse último, a autora descobre que o comportamento das professoras em relação às crianças não varia segundo a cor dos alunos, mas parece que interfere na avaliação do desempenho escolar. JáBarbosa (2004), estudando escolas também de ensino fundamental, descobre que a variável que mais afeta a avaliação das professoras não é nem a posição social, nem a "raça", mas o gênero. Meninas tendem a ser avaliadas mais positivamente do que meninos.

O remédio encontrado para combater o racismo nas escolas e que se impõe por força de lei - ou seja, as Diretrizes Curriculares Nacionais para a Educação das Relações Étnico-Raciais e para o Ensino de História e Cultura Afro-Brasileira e Africana-deve ser aplicado em todo o território nacional. Narramos apenas um caso de aplicaçãodesse remédio em uma escola de ensino médio no Rio de Janeiro na qual os alunos estão sendo expostos a essa nova pedagogia racial alinhada à visão dos movimentos negros. Nossa pesquisa ainda está no seu começo, há muitas experiências em cursoe temos, até aqui, mais perguntas do que respostas.

\section{BIBLIOGRAFIA}

AGUILLERA, Sandra Mara et al. Os Negros, os Conteúdos Escolares e a Diversidade Cultural. $2^{a}$ ed. Florianópolis, Atlende, 2002.

BARBOSA, Maria Ligia. "Diferencias de Género y Color", in R. Donald Winkler \& Santiago Cueto (orgs.). Las Escuelas de Brasil: Ios Maestros y la Evaluación de los Alumnos en Etnicidade, Raza, Género y Educación en America Latina. Santiago, Preal, 2004

BRASIL, Ministério da Educação. Diretrizes Curriculares Nacionais para a Educação das Relações Étnico-Raciais e para 0 Ensino de História e Cultura Afro-Brasileira e Africana. Brasilia, MEC/Secad, 2005.

CABRINI, Conceição; CATELLI JR., Roberto \& MONTELLATO, Andrea. História Temática. Diversidade Cultural e conflitos. 6a série do Ensino Fundamental. São Paulo, Scipione, 2005a. História Temática. 0 Mundo dos Cidadãos. 8a série do Ensino Fundamental. São Paulo, Scipione, 2005b.

CARVALHO, Irene Mello. Introdução aos Estudos Sociais. 9̣ ed. Rio de Janeiro, Fundação Getúlio Vargas, 1970, pp. 100-1. CARUSO, Carla. Zumbi, o Último Herói dos Palmares. São Paulo, Instituto Callis, 2005.

CAVALlEIRO, Eliane. "Discriminação Racial e Pluralismo nas Escolas Públicas da Cidade de São Paulo", in Educação Anti-racista: Caminhos Abertos pela Lei Federal 10639/03. Brasilia, Secretaria de Educação Continuada, Alfabetização e Diversidade, 2005.

COTRIM, Gilberto. Educação Moral \& Cívica para uma Geração Consciente. 2ograu. São Paulo, Saraiva, 1986.

CUNHA JUNIOR, Henrique et al. Os Negros e a Escola Brasileira. Florianópolis, Atlende, 1999.

DUARTE, Gleuso Damaceno. Conjuntura Atual em OSPB. Belo Horizonte, Lê, 1982.

ENCARNAC,ÃO, Marisa. "Bons Índices, Boa Escola?". Texto apresentado na Jornada dos Estudantes do PPGSA/IFCS/

UFRJ, 2005 (mimeo.). 
FAZZI, Rita de Cássia. 0 Drama Racial de Crianças Brasileiras: Socialização entre Pares e Preconceito. Belo Horizonte, Autêntica, 2004.

FRY, Peter Henry. A Persistência da Raça: Ensaios Antropológicos sobre o Brasil e a África Austral. Rio de Janeiro, Civilização Brasileira, 2005.

GALENO, Sabrina. "0 que É uma Boa Escola?". Texto apresentado na Jornada dos Estudantes do PPGSA/IFCS/UFRJ, 2005 (mimeo.).

GÓES, José Roberto Pinto de. "0 Racismo Vira Lei", in 0 Globo, 16/8/2004.

HASENBALG, Carlos. Discriminação e Desigualdades Raciais no Brasil. Rio de Janeiro, Graal, 1979.

LUCCI, Elian Alabi. OSPB - Organização Social e Políitica do Brasil. São Paulo, Saraiva, 1984

MAIO, Marcos Chor \& SANTOS, Ricardo Ventura. "Política de Cotas Raciais, 'os Olhos da Sociedade' e os Usos da Antropologia: o Caso do Vestibular da Universidade de Brasilia (UnB)", in Horizontes Antropológicos, ano 11, n.

23, janeiro/junho de 2005.

MULLER, Ricardo G. et al. Educação Popular Afro-Brasileira. 2e ed. Florianópolis, Atlende, 2002.

MUNANGA, Kabengele (org.). Superando o Racismo na Escola. Brasília, Secretaria de Ação Continuada, Alfabetização e Diversidade, MEC/BID /Unesco, 2005 [1999, 2000].

NASCIMENTO, Elisa Larkin et al. Negros, Território e Educação. Florianópolis, Atlende, 2000.

NEVES, Yasmin Poltronieri et al. As Idéias Racistas, os Negros e a Educação. 2ª ed. Florianópolis, Atlende, 2002.

NOGUEIRA, Oracy. "Preconceito Racial de Marca e Preconceito Racial de Origem", in Tanto Preto Quanto Branco:

Estudos de Relações Raciais. São Paulo, T. A. Queiroz, 1985.

OLINTO, Antonio. 0 Rei de Keto. 2a ed. Rio de Janeiro, Nórdica, 1980.

OLTAMARI, Leandro Castro et al. Os Negros, os Conteúdos Escolares e a Diversidade Cultural II. 2a ed. Florianópolis, Atlende, 2002.

PASSOS, Joana Célia dos et al. Multiculturalismo e a Pedagogia Multirracial e Popular. Florianópolis, Atlende, 2002.

ROUANET, Sergio Paulo. As Razões do lluminismo. São Paulo, Companhia das Letras, 1992.

PINGUILLY, Yves. Contos e Lendas da África. São Paulo, Companhia das Letras, 2005.

SAERP, Malu. "Centro e Periferia: um Estudo sobre a Sala de Aula". Texto apresentado na Jornada dos Estudantes do PPGSA/IFCS/UFRJ, 2005 (mimeo.).

SILVA, Ana Célia et al. As Idéias Racistas, os Negros e a Educação. 2ª̣ ed. Florianópolis, Atlende, 2002.

SOUSA, Michele Sousa. "Uma Aula de Transcrição?". Texto apresentado na Jornada de Iniciação Científica da UFRJ, 2005 (mimeo.). 